https://cssr.uitm.edu.my/2018/

5th International Conference on Science and Social Research

Le Meridien Kota Kinabalu Hotel, 5 - 6 December 2018

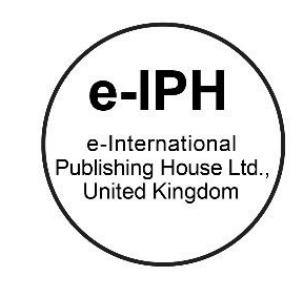

\title{
Travelling Distance for Evacuee in Multi-Storey Residential Building
}

\author{
Nurul Liyana Hanapi ${ }^{1}$, Sabarinah Sheikh Ahmad ${ }^{1}$, Azli Abd Razak² \\ ${ }^{1}$ Centre of Studies in Architecture, Faculty of Architecture Planning and Surveying, Universiti Teknologi MARA, Puncak Alam, \\ Malaysia. ${ }^{2}$ Faculty of Mechanical Engineering, Universiti Teknologi MARA, Shah Alam, Malaysia \\ liyana513123@gmail.com, sabar643@salam.uitm.edu.my, azlirazak@salam.uitm.edu.my \\ Tel: +60146291506
}

\begin{abstract}
The study on evacuation safety often an emphasis on the total evacuation time where only few research consider the distance and path needed for evacuee to evacuate the building. Thus, this study focuses on the maximum and average travelling distance need for the elderly and other evacuees in the multi-storey residential building. Pathfinder software is used in this study, and 162 simulations were tested. Results show that the escape route design and staircase condition plays a significant contribution towards occupant travel distance. Other factors such as occupancies and elderly resident also contribute to the increase in travelling distance.
\end{abstract}

Keywords: Multi-Storey, Escape Route Design, Evacuation

eISSN: 2398-4287@ 2020. The Authors. Published for AMER ABRA cE-Bsby e-International Publishing House, Ltd., UK. This is an open access article under the CC BYNC-ND license (http://creativecommons.org/licenses/by-nc-nd/4.0/). Peer-review under responsibility of AMER (Association of Malaysian Environment-Behaviour Researchers), ABRA (Association of Behavioural Researchers on Asians) and cE-Bs (Centre for Environment-Behaviour Studies), Faculty of Architecture, Planning \& Surveying, Universiti Teknologi MARA, Malaysia. DOI: https://doi.org/10.21834/ebpj.v5iSI3.2549

\subsection{Introduction}

Building design features are viewed as one of the main aspects of providing safe evacuation process. It has a direct impact towars the evacuation efficiency as it is a physically enclosed environment where people present in most of the time to perform their daily activities (Kobes, Helsloot, de Vries, \& Post, 2010). By focusing on this matter able to understand the occupant decision making in term of directional choices and how much the environmental factor influence their decision making (Vilar, Rebelo, Noriega, Teles, \& Mayhorn, 2013). Building design strategies are the design feature in providing safety egress for the occupant during an emergency (Mu et al., 2013). Occupational density is related to the building design strategies as it refers to the total number of the building occupied at one time.

Evacuation study in the multi-storey building was conducted years ago to address the specific issue during an emergency. The different type of research mainly focuses on the evacuation time, merging effect, staircase efficiency, layout design and the latest trend is on lift usage as an alternative means of transportation. Only a few studies did some consideration on the travelling distance took by the evacuee to safely evacuate out of the building.

J. Ma, Lo, \& Song, (2012), did consider the travelling distance for the occupant at every floor level but only limit to the staircase experiment. Lian, Kwok, \& Richard (2017) conduct a study on the merging effect of the evacuee also did consider the difference distance between the merging crowd and the actual flow. Results show that those from the actual flow tend to walk longer distance as to compare to the merging crowd. The phenomena can be related to the behaviour avoiding the incoming crowd creating the person to switch the actual path. Xu \& Song (2009) highlighted the position of the evacuee during emergency influence the distance of the

eISSN: 2398-4287@ 2020. The Authors. Published for AMER ABRA cE-Bsby e-International Publishing House, Ltd., UK. This is an open access article under the CC BYNC-ND license (http://creativecommons.org/licenses/by-nc-nd/4.0/). Peer-review under responsibility of AMER (Association of Malaysian Environment-Behaviour Researchers), ABRA (Association of Behavioural Researchers on Asians) and cE-Bs (Centre for Environment-Behaviour Studies), Faculty of Architecture, Planning \& Surveying, Universiti Teknologi MARA, Malaysia.

DOI: https://doi.org/10.21834/ebpj.v5iSI3.2549 
evacuee. Those walking in the inner-side area will result in a shorter walking distance as the probability of those from the outer-side to change direction is more substantial. Jiang et al., (2009) did consider the average evacuation distance for every scenario conducted. From the data, it shows that although the building layout is small, simple and straight forwards, the distance took by the evacuee are varies. This data indicates that the occupant travelling distance is not solely depending on the building design but another factor as well.

There some study that might consider the total evacuation path but the distance are calculated based on the straight line (Nilsson, Johansson, \& Frantzich, 2009). Although the basic travelling distance can be recorded like so, during an emergency, the occupant is not walk in a straight path. The distance can be recorded only to gauge the minimum travelling distance of the evacuee. There is a specific condition that might cause the evacuee to change the walking direction such as obstacle, overtake the slow-moving evacuee, finding other alternative exit and many other reasons (Jiang et al., 2009; Y. Ma, Lee, \& Shi, 2017). Some researcher highlighted the effect of the visibility towards the occupant travelling distance (Fang et al., 2012; Jeon, Kim, Hong \& Augenbroe, 2011).

During an emergency, the life of the evacuee is more dependent on the travelling time to compare to travelling distance. Still, it believed that distance contributes to the ability of every evacuee to travel in a long-distance during an emergency. Travelling used up the energy and not all individual has the same energy to transport themselves to safety. Those with a disability and the elderly might have a limited amount of energy where they can become tired before reach the target destination. Those this paper focused on travelling distance of evacuee in multi-storey residential building and made some comparison between the elderly resident and the normal evacuee to see the differences between both groups.

\subsection{Method}

Pathfinder is used as a simulation software as it provides the researcher with some flexibility in making some changes suited to the objective of the study. As for the building model, the typical layout of the public multi-storey residential building was used. The author chooses the building based on the number of building built and future development of the building, making the data collected become more significant. 17 storey building with a total of 240 unit was used as a base for the data collection.

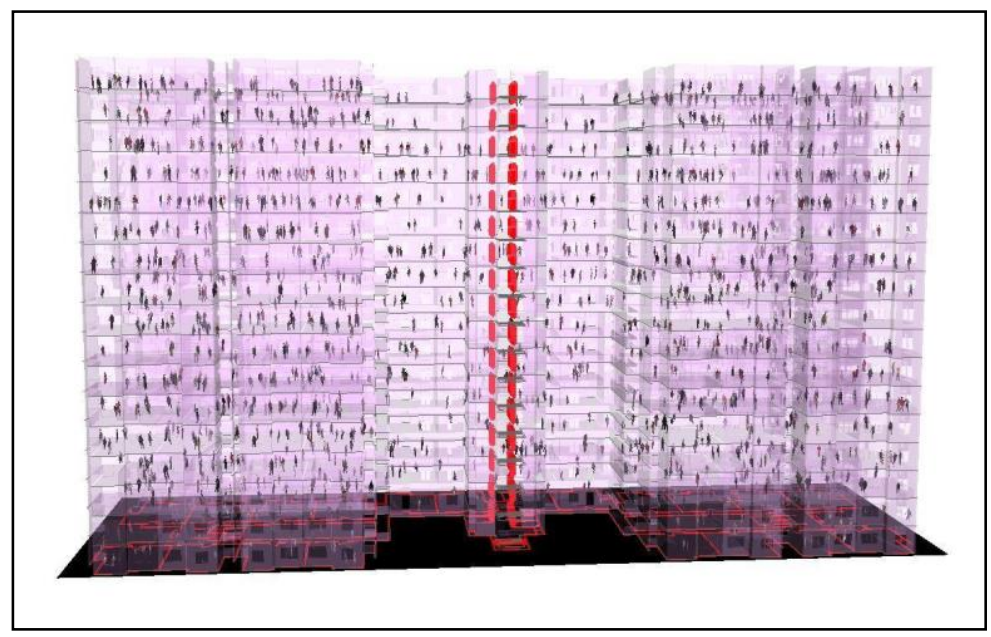

Fig. 1: Building model based on the typical layout of public building in Malaysia.

\begin{tabular}{ll}
\multicolumn{2}{c}{ Table 1: Value input for evacuee movement } \\
\hline Evacuee & Value \\
Speed & Max $-2.6 \mathrm{~m} / \mathrm{s}$ \\
& Min $-1.3 \mathrm{~m} / \mathrm{s}$ \\
Size & $40 \mathrm{~cm} \times 40 \mathrm{~cm}$ \\
Acceleration time & $1.1 \mathrm{sec}$ \\
Reduction factor & $1 \mathrm{sec}$ \\
Slow factor & 0.1 \\
Persist time & $1 \mathrm{sec}$ \\
Comfort distance & 0 \\
\hline
\end{tabular}

Since the study, focuses on the effect of evacuee travelling distance, three variables were considered in this study. First is the impact of occupant density, where the number will be determined based on the number of household per unit. Still, the distribution of the evacuee is random throughout the building to represent the variety of occupancy in one building. Secondly, is the number of elderly based on the percentage of the elderly in every occupancy. The number of elderly believe will contribute to the increase of travelling distance as slow speed of elderly will force the other evacuee to change the path and overtake the slow occupant. Last is the 
availability of the staircase towards the evacuation process. The staircase was chosen due to the high dependency during an emergency, especially on the multi-storey building. The consideration for the movement of an evacuee is discussed in Table 1.

Three staircase condition were tested when all of the staircases are available, and one of the staircases (side and centre) were closed during the evacuation. The walking speed of the evacuee will be based on the speed of the adults and elderly in IMO, (2007). As for the shoulder width, this study will use a $40 \mathrm{~cm} \times 40 \mathrm{~cm}$ as it indicated the space occupied in a dense crowd and was used by many Asian researchers (Göransson, 2012; Varas, Cornejo, Mainemer, Toledo, \& Valdivia, 2007; Zheng, Jia, Li, \& Zhu, 2011).

162 simulation test was conducted in this paper based on different case and scenario. The detail of the scenario is shown in table 2 , and the three cases were shown in table 3 . The study conducted focuses on the three variable mentions previously together with three different escape route width to see whether the dimension contributes to the travelling distance.

\begin{tabular}{|c|c|c|c|c|c|c|c|c|c|}
\hline \multirow[t]{2}{*}{ scenarios } & \multicolumn{3}{|c|}{ Number of occupant } & \multicolumn{4}{|c|}{ Percentage of elderly } & \multicolumn{2}{|l|}{ Group } \\
\hline & 1478 & 1700 & 2100 & $0 \%$ & $7 \%$ & $10 \%$ & $15 \%$ & Elderly & Adults \\
\hline $\mathrm{Ae} 1$ & $x$ & & & & $x$ & & & $x$ & \\
\hline $\mathrm{Ae} 2$ & & $x$ & & & $x$ & & & $x$ & \\
\hline $\mathrm{Ae} 3$ & & & $x$ & & $x$ & & & $x$ & \\
\hline $\mathrm{Be} 1$ & $x$ & & & & & $x$ & & $x$ & \\
\hline $\mathrm{Be} 2$ & & $x$ & & & & $x$ & & $x$ & \\
\hline $\mathrm{Be} 3$ & & & $x$ & & & $x$ & & $x$ & \\
\hline $\mathrm{Ce} 1$ & $x$ & & & & & & $x$ & $x$ & \\
\hline $\mathrm{Ce} 2$ & & $x$ & & & & & $x$ & $x$ & \\
\hline $\mathrm{Ce} 3$ & & & $x$ & & & & $x$ & $x$ & \\
\hline $\mathrm{Aa} 1$ & $x$ & & & & $x$ & & & & $x$ \\
\hline Aa2 & & $x$ & & & $x$ & & & & $x$ \\
\hline Aa3 & & & $x$ & & $x$ & & & & $x$ \\
\hline $\mathrm{Ba} 1$ & $x$ & & & & & $x$ & & & $x$ \\
\hline $\mathrm{Ba} 2$ & & $x$ & & & & $x$ & & & $x$ \\
\hline Ba3 & & & $x$ & & & $x$ & & & $x$ \\
\hline Ca1 & $x$ & & & & & & $x$ & & $x$ \\
\hline $\mathrm{Ca} 2$ & & $x$ & & & & & $x$ & & $x$ \\
\hline Ca3 & & & $x$ & & & & $X$ & & $X$ \\
\hline \multicolumn{10}{|c|}{$\begin{array}{l}\text { *ABC (in capital) indicate the percentage of the elderly } \\
{ }^{*}(e) \text { indicate the elderly evacuee and (a) indicate the adult evacuee } \\
\text { * } 123 \text { indicate the number of occupancy (1 indicates low occupancy, } 2 \text { medium occupancy and } \\
3 \text { high } \\
\text { occupancy) }\end{array}$} \\
\hline \multicolumn{10}{|c|}{ Table 3: Value input for evacuee movement } \\
\hline Case & \multicolumn{5}{|c|}{ Staircase condition } & \multicolumn{4}{|c|}{ Escape route width } \\
\hline Case 1 & \multicolumn{5}{|c|}{ All of the staircase is open } & \multirow{3}{*}{\multicolumn{4}{|c|}{$\begin{array}{l}\text { All of the cases will be tested together } \\
\text { with the increase of escape route } \\
\text { dimension from } 1300 \mathrm{~mm}, 1500 \mathrm{~mm} \\
\text { and } 1800 \mathrm{~mm} \text {. }\end{array}$}} \\
\hline Case 2 & \multicolumn{5}{|c|}{ Centre staircase is closed } & & & & \\
\hline Case 3 & \multicolumn{5}{|c|}{$\begin{array}{l}\text { One side of staircase is } \\
\text { closed }\end{array}$} & & & & \\
\hline
\end{tabular}

\subsection{Result and Discussion}

From the simulation test, the study gathers the maximum distance and mean travel distance for both elderly and adults in every test that has been conducted. From there, it allows the author to make some comparison between the distances travelled by both groups. Figure 2 shows the maximum travel distance between the elderly and adults based on different case study and scenarios. The colour of the line indicates the number of occupants where the different line style indicates the percentage of the elderly. Every segment represents a different case scenario where three different escape route dimension also considered in this study.

The longest path is the adults from case study 3 (437.2 meters), which has the highest occupancy and highest percentage of elderly. The shortest distance is from the elderly in case 2 (191 meters), which has the lowest occupancy but a higher percentage of the elderly. From this data, the author can gauge the shortest and longest distance under the categories of maximum travel distance took by the occupant in the public multi-storey building in Malaysia. When the author tracked down the location of the highest score, the evacuee is located at the highest floor, far from the staircase (located at the closed staircase) and keep travel back and forth between available staircases. As for the lowest distance, the evacuee situated on the lowest floor, close to the available staircase and did not travel between staircases making the evacuee travel much lesser than the other evacuee.

As for the travelling distance based on the three case study, case study 1 shows the lowest overall maximum travelling distance. This data can be related to the number of staircase availability where it contributes to a significant contribution to the travelling distance. As for the case 2 and 3 which has the same amount of the staircase but different area of the close staircase, both cases recorded a different set of travelling distance but did has an increase in travelling distance as to compare to case 1. Case 2 and 3 
have higher travelling distance because the decreasing number of staircase forcing the available staircase to cater to a high number of evacuee which significantly contribute to the issue of bottleneck and stagnation.

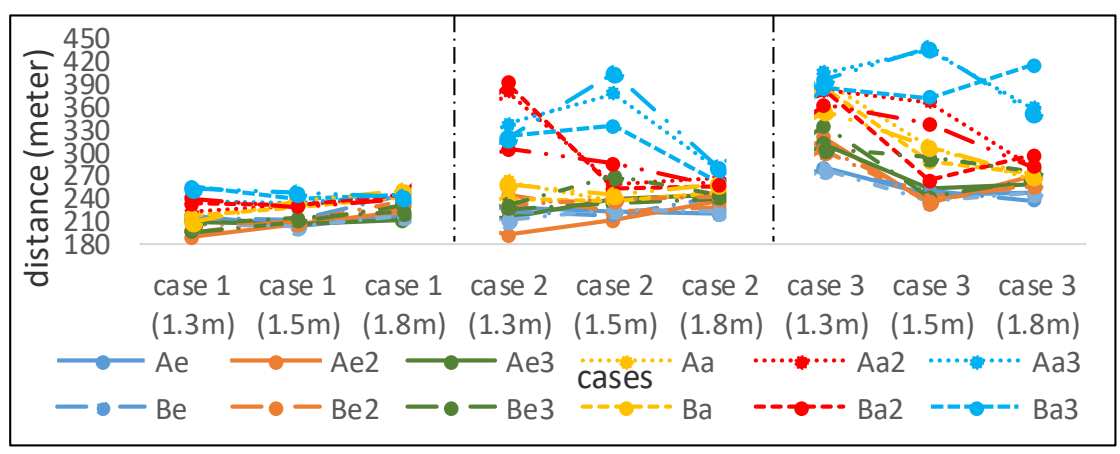

Fig. 2: Maximum travel distance between elderly and adults in different staircase scenarios.

If this study tries to compare the travelling distance between the maximum path for the elderly and adults, there are not much different that can be seen. It is due to the data taken by the author only consider the maximum travel path by an individual in a group from separate case study and scenario. Thus a comparison should be made based on the average travelling distance caused by the elderly and the adults, which will be discussed in figure 3 .

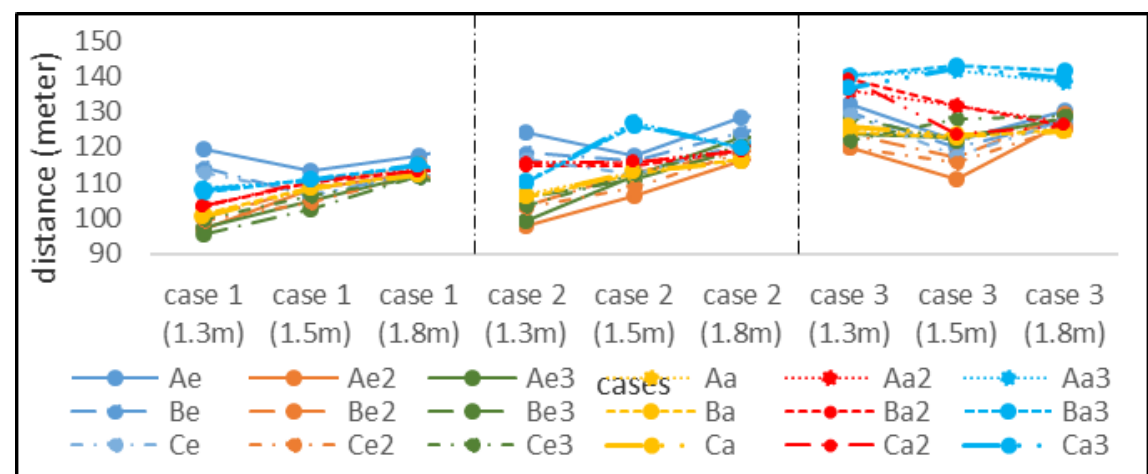

Fig 3: Mean travel distance between elderly and adults is different staircase scenarios

It is hard to see the actual data if the consideration only on an individual who is travel the farthest in every simulation test conducted. Thus, a mean travel distance will provide much information as it allows for the average distance took by every evacuee in the building.

The result shows that the increase of elderly occupant and density did not play a significant contribution towards the travelling distance. In contrast, the rise in the escape route dimension did have a significant contribution to the travelling distance. The wider the escape route, the longer it takes for the evacuee to travel. The data can be easily explained in the landing of staircases (refer figure 4) where wider escape route will increase the turning distance of evacuee as to compare to the smaller escape route.

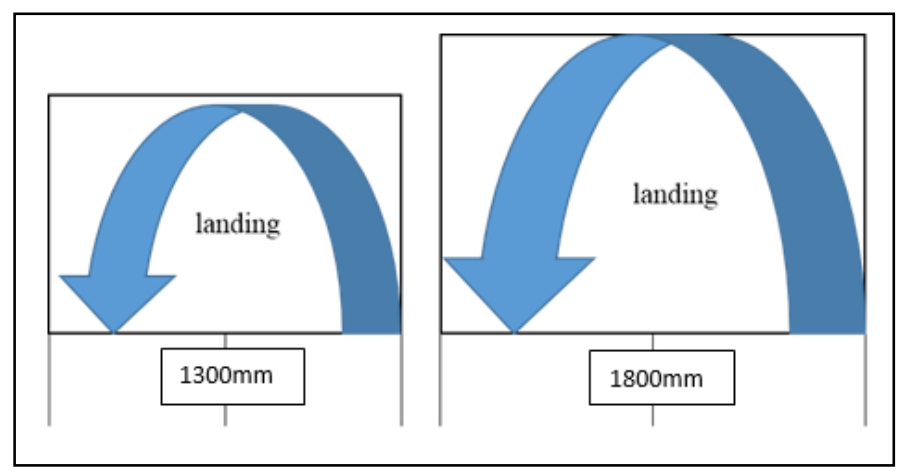

Fig 4: Different curvature that represent the path took by the outer side of evacuee in the landing between $1300 \mathrm{~mm}$ and $1800 \mathrm{~mm}$ staircase width. 


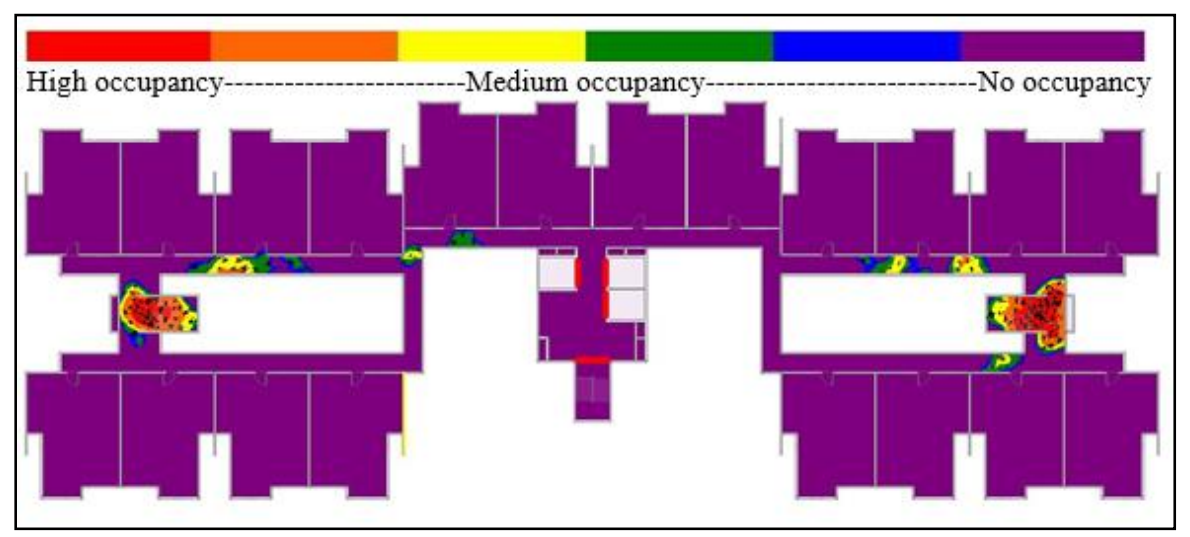

Fig 5: Level of staircase service for case 2

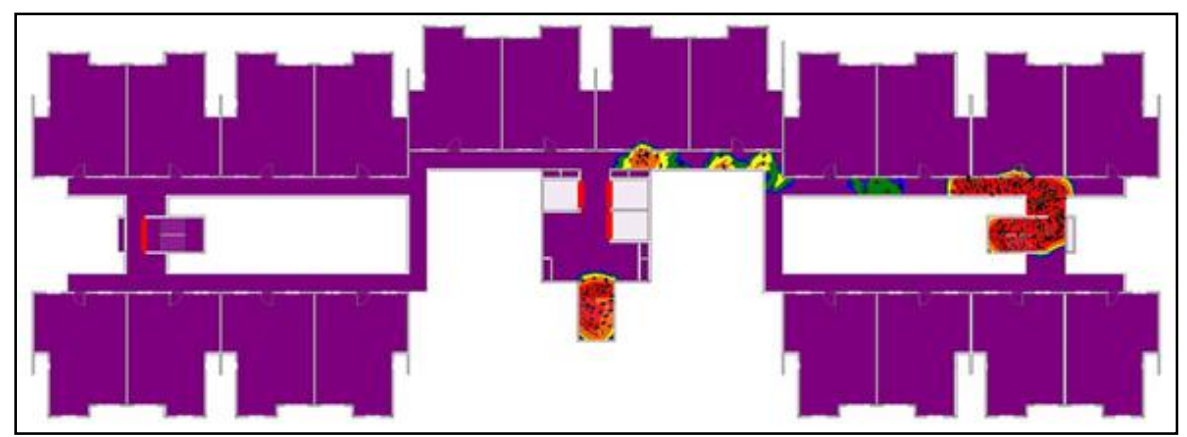

Fig 6: Level of staircase service for case 3

Results from every case show a significant increase in travelling distance from case 1,2 and 3. Data shows that on average case 1 indicates the lowest travel distance where case 3 shows highest travelling distance. Although case 2 and 3 have the same amount of staircase, the location plays a role in determining the distance taken by the evacuee. This because the distribution of evacuee in case 3 is imbalance causing the evacuee in closed staircase need to travel much further. The imbalance of evacuee also causing one staircase to have high occupancy. Figure 5 and 6 represent the difference between the levels of service at every staircase. Figure 6 shows a high stagnation occurs at the side staircase that causes the occupant to spill over at the corridor area.

\subsection{Conclusion}

In this paper, the author focuses on the different variable to see the effect on the occupant travelling distance in a multi-storey building. What can conclude is that many factors affecting the evacuee travelling distance but escape route design play a significant contribution to the travelling distance. The increasing number of the staircase will reduce the staircase usage, thus reducing the impact of stagnation. It will increase the evacuation efficiency and reduce the chances of evacuee travelling back and forth between available staircases.

The distribution of evacuee also plays a significant contribution where the location of staircases and exit need to be correctly designed to ensure a balance in crowd dispersal. Next is the width of the escape route design must not necessarily be more significant. Although wider escape route did contribute to a lesser evacuation time, it does create longer travelling distance for the evacuee. Longer travelling distance means more energy needed for the evacuee to travel. If it might not be an issue for healthy adults, but those with limited physical capability might face a higher risk to become a trap in the building.

The author provides a significant finding in factor contributes to longer travelling distance. Thus the future study can consider the ways to minimize the travelling distance mainly catering the need of those with the limited physical ability to ensure maximum safety for every evacuee.

\section{Acknowledgement}

The authors gratefully acknowledge the help of the UiTM in providing the Internal Research Grant (600-IRMI/ MyRA 5/3/BESTARI (040/2017) and Ministry of Education for providing a scholarship under MyBrain15. The authors are also thankful to Thunderhead Engineering for providing free licensing on Pathfinder simulation software that was used in this research. 


\section{References}

Fang, Z. M., Song, W. G., Li, Z. J., Tian, W., Lv, W., Ma, J., \& Xiao, X. (2012). Experimental study on evacuation process in a stairwell of a high-rise building. Building and Environment, 47(1), 316-321. https://doi.org/10.1016/j.buildenv.2011.07.009

Göransson, O. B. (2012). System optimum during the evacuation of pedestrians from a building A minor field study, (September)

IMO, 2007. Guidelines For Evacuation Analyses For New and Existing Passenger Ships, International Maritime Organization, MSC/Circ. 1238.

Jeon GY, Kim JY, Hong WH, Augenbroe G. (2011) Evacuation performance of indi- viduals in different visibility conditions. Building and Environment; 46(5):1094e103.

Jiang, C., Li, W., Hu, C., Xiong, Y., Ding, H., \& Chow, W. K. (2009). Emergency evacuation in places for public entertainment in Mainland China. Building and Environment, 44(1), 169-176. https://doi.org/10.1016/j.buildenv.2008.02.006

Kobes, M., Helsloot, I., de Vries, B., \& Post, J. G. (2010). Building safety and human behaviour in fire: A literature review. Fire Safety Journal, 45(1), 1-11. https://doi.org/10.1016/j.firesaf.2009.08.005

Lian, L., Kwok, Y., \& Richard, K. (2017). Pedestrian merging behavior analysis: An experimental study. Fire Safety Journal, 91(February), 918-925. https://doi.org/10.1016/j.firesaf.2017.04.015

Ma, J., Lo, S. M., \& Song, W. G. (2012). Cellular automaton modeling approach for optimum ultra high-rise building evacuation design. Fire Safety Journal, 54, 57-66. https://doi.org/10.1016/j.firesaf.2012.07.008

Ma, Y., Lee, E. W. M., \& Shi, M. (2017). Dual effects of guide-based guidance on pedestrian evacuation. Physics Letters A (Vol. 381). https://doi.org/10.1016/j.physleta.2017.03.050

Mu, H. L., Wang, J. H., Mao, Z. L., Sun, J. H., Lo, S. M., \& Wang, Q. S. (2013). Pre-Evacuation Human Reactions in Fires: An Attribution Analysis Considering Psychological Process. Procedia Engineering, 52, 290-296.

Nilsson, D., Johansson, M., \& Frantzich, H. (2009). Evacuation experiment in a road tunnel: A study of human behaviour and technical installations. Fire Safety Journal, 44(4), 458-468. https://doi.org/10.1016/j.firesaf.2008.09.009

Varas, A., Cornejo, M. D., Mainemer, D., Toledo, B., \& Valdivia, J. A. (2007). Cellular automaton model for evacuation process with obstacles, 382, 631-642. https://doi.org/10.1016/j.physa.2007.04.006

Vilar, E., Rebelo, F., Noriega, P., Teles, J., \& Mayhorn, C. (2013). The influence of environmental features on route selection in an emergency situation. Applied Ergonomics, 44(4), 618-27. https://doi.org/10.1016/j.apergo.2012.12.002

Xu, X., \& Song, W. (2009). Staircase evacuation modeling and its comparison with an egress drill. Building and Environment, 44(5), $1039-1046$. https://doi.org/10.1016/j.buildenv.2008.07.009

Zheng, Y., Jia, B., Li, X.-G., \& Zhu, N. (2011). Evacuation dynamics with fire spreading based on cellular automaton. Physica A: Statistical Mechanics and Its Applications, 390(18-19), 3147-3156. https://doi.org/10.1016/j.physa.2011.04.011 